\title{
Tareas para el filósofo en tiempos de pandemia
}

\author{
Tasks for the philosopher in times of pandemics
}

Dra. María de Paz Universidad de Sevilla maria.depaz@hotmail.com

Orcid: http://orcid.org/00000003-3703-4477

Data de recebimento: 31/08/2020 Data de aceite: 10/10/2020

\section{Resumen}

El objetivo de este artículo es defender la tesis de que no existen tareas específicas del filósofo durante una pandemia. Las tareas del filósofo no cambian durante un período de crisis. Al mismo tiempo, buscamos reivindicar la importancia del filósofo en nuestras sociedades.

Palabras clave: filosofía, Covid-19, pensar.

\section{Abstract}

The aim of this paper is to defend the idea that there are no specific tasks for a philosopher during pandemics. Philosopher's tasks do not change in times of crisis. We also try to vindicate the relevance of the philosopher in our societies.

Key-words: philosophy, Covid-19, thinking 
Desde principios de 2020 los filósofos han escrito mucho sobre cómo reaccionar, tanto desde un punto de vista teórico como práctico a esta extraña situación en que nos encontramos por la propagación del virus Covid-19. Al principio, hacia el mes de marzo y durante todo abril, los periódicos se llenaron de reacciones de grandes figuras contemporáneas como Agambem, Žižek, Butler, Byung-Chul Han, y de otras menos conocidas como A. Krenak, R. Rodríguez Aramayo o M. Galindo. En ese momento, daba la impresión de que muchos veían la pandemia como una oportunidad, como una ocasión de pararse a pensar y de consultar a los expertos en pensar cómo afrontar esta 'nueva' situación. Con esto no quiero decir que estos autores sean un conjunto de oportunistas u ocasionalistas que buscan una excusa para que su nombre salga en los medios. Pero de repente, los periodistas, quizá el público, quizá todos, vieron que era necesario, casi imperativo, publicar un artículo de un filósofo ${ }^{1}$ hablando de la pandemia o de la multitud de temas relacionados con ella, como el teletrabajo, el desastre psicológico del encierro, el estado policial que acompaña al confinamiento, las secuelas de la falta de contacto físico con los seres queridos (para esto también estaban los psicólogos), etc. Pasados unos meses, el número de este tipo de artículos parece haber descendido, o quizá es simplemente la pereza estival, como si el verano no acompañase el pensamiento -aunque no debemos olvidar que la pandemia es global, lo que implica que no es verano en casi medio mundo, pero eso es otra historia. Y aquí nos planteamos, en esta revista, un número dedicado precisamente a esta cuestión, volviendo a la carga cuando la fiebre del filósofo parece haber pasado. Sin embargo, la idea no es original, pues multitud de revistas han anunciado llamadas de artículos acerca de la pandemia o de temas asociados. Y lo que quiero decir es que, en realidad, está bien que así sea.

En este artículo, pese a la situación en la que todavía nos encontramos y que parece que nos encontraremos aún cuando salga publicado, voy a defender una tesis que no cuadra con el título y que quizá resulte un tanto polémica. Frente a la pléyade de autores que han escrito sobre esta cuestión, la tesis de fondo que propongo y que trataré de ilustrar con ejemplos es que no hay tareas específicas del filósofo en tiempos de pandemia. Defiendo, así, que el trabajo del filósofo no cambia esencialmente, y que no debería cambiar, ni tampoco debería sorprendernos que los filósofos escriban sobre un tema de tanta actualidad y que tampoco deberíamos quedarnos perplejos -como a mí misma me ha pasado- por ver multitud de artículos simplemente escritos por filósofos. Por si la idea no queda clara, lo que vengo a defender de manera más positiva -junto a la tesis negativa de que el filósofo no tiene tareas específicas en tiempos de pandemia- es que deberíamos estar acostumbrados a la presencia del filósofo en los medios de comunicación, en la sociedad y, por qué no, en nuestro día a día. En definitiva, el confinamiento, el virus, la pandemia y las nuevas condiciones políticas y sociales no han hecho más importantes a los filósofos, porque ya lo eran, porque lo son y porque si lo fueran más, tal vez -y solo tal vez, insisto-, podríamos hacer algunas cosas mejor.

\section{Lo inmediato: sociedad, política y ética}

Pretendo ilustrar esta tesis acerca de la no especificidad de las tareas del filósofo durante una pandemia con ejemplos. Voy a estructurar estos ejemplos a partir de algunas de las áreas de trabajo de que se ocupa la filosofía, y esto lo hago sin ánimo de exhaustividad, pues no pretendo abarcar en este artículo todos los ámbitos de la filosofía, sino simplemente plantear algunas cuestiones posibles y plausibles. Así, comenzaré por una de las áreas que ha recibido más atención y que parece ser de más actualidad por lo mucho que nos afecta: se trata de las cuestiones relacionadas con lo social, donde voy a agrupar también lo político y lo ético, e incluso lo económico. Porque toda sociedad es política y todo grupo humano -eso es lo que entiendo por sociedad- tiene un comportamiento ético (o varios).

Desde el punto de vista socio-político son muchas las cuestiones que se han planteado durante estos meses. Desde el principio, algunas voces se alzaron contra el estado policial y el excesivo control ciudadano

1 Un evaluador me exigía que definiera 'filósofo', me niego a hacerlo y dejo a la inteligencia del lector la comprensión del uso del término en el texto. Por otra parte, todos los señalados arriba, con excepción de Krenak (hasta dónde sé) tienen formación filosófica reglada. 
al que el confinamiento, en pro de la salud, estaba llevando. Podemos leer los primeros artículos de Agamben (2020) en febrero hablando de la promulgación del estado de excepción en Italia, pero que ocurrió en muchos países. Efectivamente, ha habido un estado policial con un excesivo control ciudadano que ha sido denunciado por muchos autores. Algunos de ellos lo han hecho desde una perspectiva más o menos 'conspiranoica', como fue el primer artículo de Agamben, donde denunciaba la 'invención' de una epidemia para instaurar estados de excepción. Otros, como Berardi (2020), lo han denunciado desde una postura más mesurada, analizando el inmovilismo y la 'pasivización' a que han llevado estos meses. Pero no se trata aquí de analizar la situación de pandemia, sino de mostrar, que el filósofo ya tiene esa tarea de denunciar injusticias sociales y estados policiales haya o no pandemia. Y, en efecto, sin negar que el estado policial se ha exacerbado en muchos países en los últimos meses, parece ingenuo pensar que es solo la excusa de la pandemia la causante de ello. Llevamos décadas, sometiéndonos a diversos controles, a escrutinio de cámaras, cediendo nuestros datos a la tecnología y la mayoría de las veces lo hacemos 'por nuestra seguridad': pase por el escáner en el aeropuerto, quítese los zapatos, no lleve líquidos en el avión, permita que le grabemos, entregue su ubicación..., todo ello "por su seguridad". Porque cuanto más vigilados estemos, estaremos más seguros. Porque cuantas menos libertades tengamos, cuanto más control suframos, estaremos más seguros. Y poco a poco hemos ido cediendo parcelas de nuestra privacidad para sentirnos más seguros. Y la mayoría de las veces ni siquiera nos hemos preguntado si el precio no era demasiado alto.

La última aberración de este estado policial ha sido contemplar en mi país (y seguramente ha ocurrido en otros) a muchos ciudadanos haciendo de policías y denunciando desde sus ventanas a alguien que salía a la calle sin mascarilla, que se sentaba en un banco, que paseaba, o que excedía la distancia a la que podía pasear con su perro. Si todos los ciudadanos nos convertimos en policías, estaremos mucho más seguros, tanto como esa seguridad que puede hoy sentirse en ciudades como Wisconsin gracias a esas patrullas de civiles armados. Suena a destino ideal de vacaciones.

Y lo mejor de todo ha sido no ver ni una sola pronunciación en contra de este estado policial por parte de nuestros políticos. En España se ha utilizado la ley más represiva que ha existido en democracia -la llamada 'ley mordaza' (Ley Orgánica 4/2015, de 30 de marzo) ${ }^{2}$ - para facilitar actuaciones policiales durante el estado de alarma. Una ley que el actual gobierno prometió derogar. Pero que hoy ya nadie discute y las promesas de derogación parecen haber pasado al cajón de-sastre del olvido político.

En definitiva, este estado policial de hipercontrol ciudadano, de pérdida de la privacidad, lleva años fraguándose y hace tiempo que lo venden como algo beneficioso para nosotros. Igual que ahora nos lo han vendido por cuestiones de salud, pero solo es un aliciente más. Varias voces se han levantado aquí y allá contra ello, advirtiendo de los peligros de la tecnología, de la invasión de la privacidad que esa esfera supone, pero estamos poco dispuestos a hacer caso, porque la salud y la seguridad parecen más importantes que la libertad y la responsabilidad personal. Es decir, la Covid-19 no ha generado un estado más autoritario del que ya existía, simplemente algunos lo han sentido más y es quizá una excusa para ampliar la restricción de libertades. ${ }^{3}$ Hagamos de esta excusa una razón para pensar y para actuar responsablemente en contra de aquello que consideramos una vigilancia excesiva.

Efectivamente, la responsabilidad es algo a lo que se apela poco desde el panorama político. Muchos sabemos que pocos políticos son ejemplo de responsabilidad, y aquí da igual el país, la lacra es internacional. Responsabilidad es una palabra que suena poco, suena poco en la escuela, suena poco en las comunidades de vecinos y suena poco en los parlamentos. Se han creado numerosos mecanismos de disolución de la responsabilidad, como si nadie tuviera nunca la culpa de lo que pasa. Yo diría que esto ocurre desde hace

2 Se trata de la Ley Orgánica de protección de la seguridad ciudadana, que entró en vigor el 1 de Julio de 2015 que ha suscitado muchas polémicas, incluso en el ámbito internacional con denuncias por parte de Amnistía Internacional, el diario New York Times en carta a la Comisión Europea, etc.

3 Esta afirmación merece matizarse. Es muy posible que localmente la pandemia sí se haya utilizado como excusa para aumentar la restricción de libertades. Ejemplos a nivel local son en España la prohibición por parte de los gobiernos autonómicos de Galicia y País Vasco de ejercer el derecho a voto a poblaciones que estaban confinadas, negando así a algunos ciudadanos un derecho constitucional. Agradezco a Antonio Puech esta puntualización. 
tiempo y viene desde arriba, los estados están fuertemente estructurados en diferentes escalafones, lo mismo ocurre con las empresas, los bancos, y todos los servicios públicos en general. De tal forma que cuando se trata de denunciar la irresponsabilidad de una determinada acción y señalar a los culpables, las cadenas son tan complejas que esta queda diluida. Igual, el ciudadano aprende a diluir su responsabilidad, en lugar de hacerse cargo de lo suyo, llevar su mascarilla, recoger los detritos de su perro, educar a sus hijos para que vivan en sociedad, es más fácil que otro le señale, que otro le denuncie y que él denuncie a otro y que otro haga lo que por responsabilidad a él le corresponde. Es mejor tener un 'papá-estado' que resuelva los problemas, un vecino que denuncia y al que yo puedo denunciar después, que hacerme cargo de mis errores y de mis elecciones. Como me dijo un amigo, 'somos más obedientes que responsables'.

Obviamente, una ética de la responsabilidad tendría que asentarse tanto de arriba a abajo como de abajo a arriba. Es decir, las personas que más aparecen en los medios, que en general son los políticos, deberían comenzar por adoptarla. Pero también debería ser una prioridad en nuestras escuelas, donde no solo primen los contenidos de enseñanza, sino también los valores. No se trata de un adoctrinamiento a la infancia, sino de que niños y adolescentes aprendan a vivir en sociedad y eso siempre implica responsabilidad. Cabría incluso pensar, si en un estado en el que los ciudadanos son más responsables y, por tanto, menos infantilizados no perdería sentido el estado policial y la sobrevigilancia. Pero en realidad es mucho más fácil enseñar contenidos que valores. Qué gran tarea para los filósofos la implicación en la educación. Todos los países saben, aunque lo oculten en muchas ocasiones, que la educación es la parcela más importante de un gobierno. Quien controla la educación controla el futuro de un país, y el presente. La educación configura el ser de lo social en muchos aspectos, y esa falta de valores, que debe ser denunciada haya o no epidemia, es un problema para nuestras sociedades.

Más allá de la responsabilidad, cabe pensar en otros valores que son socialmente fundamentales, como la solidaridad. Casi nadie estaría en contra de que se eduque mostrando la importancia que tiene la solidaridad. El problema viene cuando se plantea quién merece ser el destinatario de esa solidaridad. Quizá no el que no piensa como yo, el que no tiene mi color de piel, el que no vive en el mismo continente, el que no es de mi clase social, el que no tiene la misma inclinación sexual que yo. ¿Merece solidaridad el inmigrante que se juega la vida para cruzar el Mediterráneo y llegar de África a Europa? ¿Merece solidaridad el indígena que lucha porque no destruyan la selva en la que habita? ¿Merece solidaridad el musulmán? Durante el confinamiento, hemos visto noticias de acciones ciudadanas solidarias, de contribuciones anónimas para ayudar a los que menos tienen, de vecinos haciendo la compra a población de riesgo para que estos no tuvieran que salir. ¿Habríamos hecho lo mismo si mi vecino fuera gitano o musulmán o extranjero?

Todas estas preguntas cabe hacerlas también a nivel global. La solidaridad no se lleva solo a cabo mediante acciones individuales. En la Unión Europea, durante estos meses, al hablar de los pactos de reconstrucción se ha señalado la necesidad de solidaridad entre los países del norte y los países del sur, o entre los países más ricos y los más pobres. Ha habido un verdadero conflicto sobre cómo operar la reconstrucción tras el desastre económico y, por tanto, social, de la pandemia. Esta situación tampoco es, en realidad, nueva. Lo mismo ocurrió durante la pasada crisis económica iniciada en 2008 y lo mismo ocurre cada vez que hay una crisis migratoria. El pensamiento de la mayoría de los estados no es global, el pensamiento de la Unión Europea tampoco es global. Pocos piensan que las acciones de deforestación en la Amazonia brasileña tienen consecuencias en la calidad del aire italiano. $\mathrm{O}$ que no respetar en China los protocolos de contaminación afecta al aire que respiran en Australia. El mundo en que vivimos es global, el efecto mariposa no se restringe a fenómenos atmosféricos. Eso requiere de políticas globales. Y no hacía falta una pandemia para saber esto. Que la filosofía política se ocupe de pensar modelos más allá del estado nación no es una necesidad nueva, como tampoco lo es educar pensando de manera global. Una Unión Europea solidaria entre sí sería algo deseable. Más deseable sería aún una Unión Europea solidaria no solo con Europa. Europa tampoco es una isla completa en sí misma, sigue siendo una parte de la tierra y los europeos están tan ligados a la humanidad como el resto de los hombres. Las políticas económicas y sociales deben trascender la utópica unidad del estado nación, pues si las multinacionales piensan más allá, ¿por qué no también los ciudadanos y sus gobernantes? 
Por otra parte, cabe preguntarse, al hilo de esta cuestión de los valores de responsabilidad y solidaridad en educación, en sociedad y en política, si no tendrían también una incidencia en economía. Durante la crisis de 2008 se pusieron de moda no solo los economistas, sino también los filósofos de la economía, como si aquella crisis representara una oportunidad para esta área. Si la economía está presente en nuestro día a día, y nadie negará que así es, entonces pensar la economía es un trabajo que no es solo necesario en tiempos de crisis, sino en cualquier época. Toda crisis conlleva una acentuación de las desigualdades, y desde los años 80, cuando quizá el estado del bienestar en los países europeos y en Estados Unidos alcanzó su culmen, las desigualdades han crecido exponencialmente. El modelo económico capitalista, basado en la premisa no demostrada del crecimiento ilimitado (cf. Berardi 2020), está fuertemente asentado sobre valores insolidarios y altamente irresponsables -lógicas extractivistas, explotación de personas y recursos, privatización de servicios básicos, etc.- y encaja muy bien con una educación acrítica e infantilizada que sustituye al ciudadano por el consumidor (cf. Micheá 1999). Uno de los problemas es que este modelo genera enormes desigualdades, que son más patentes en épocas de crisis, pero que son necesarias para el mantenimiento del modelo. Se ha dicho que este virus, como cualquier enfermedad, no distingue entre ricos y pobres, otra de las razones para tratar a esta epidemia como un fenómeno global. Sin embargo, esta afirmación, que desde un punto de vista biológico es estrictamente cierta, se torna falsa cuando tenemos en cuenta las condiciones socio-económicas de los sujetos a los que afecta la enfermedad. En la medida en que la sanidad ha sido, junto con la educación, uno de los negocios más lucrativos del régimen capitalista, no puede ser cierto que no haya diferencias. Efectivamente, todos podemos morir por este virus. Pero aquellos que viven en condiciones sanitarias más insalubres, que no pueden, por condiciones laborales o personales mantener la distancia social de seguridad, que no tienen acceso a un sistema sanitario que les atienda cuando enferman son, sin duda alguna, mucho más vulnerables. Como dice Butler (2020): "El virus por sí solo no discrimina, pero los humanos seguramente lo hacemos, modelados como estamos por los poderes entrelazados del nacionalismo, el racismo, la xenofobia y el capitalismo". Y eso se traduce, de manera lógica, en la discriminación de los más desfavorecidos, de los que menos acceso tienen a condiciones de vida saludables. La pregunta es si era necesaria una pandemia para que las voces se alcen denunciando la necesidad de que existan servicios de salud públicos de calidad. ¿Solo pensamos en la salud cuando estamos enfermos o cuando la enfermedad nos amenaza? Si es así, es un error, pues la tarea de pensar en el beneficio de servicios como la sanidad pública, la necesidad de denunciar las privatizaciones y el hacer negocio con la vida de los ciudadanos no puede ir asociada a tiempos de crisis.

En efecto, la restricción de libertades, los problemas de la tecnología, la necesidad de pensar en el otro, la responsabilidad individual y colectiva, el sistema educativo, el régimen económico, los servicios públicos... son cuestiones sobre las que se debe pensar en todo tiempo y lugar, sobre las que debe haber artículos para todos los públicos y para especialistas en los medios de comunicación; sobre las que hay que debatir en aulas, en bares y en parlamentos. Cuestiones demasiado importantes, demasiado apremiantes para pensarlas solo mientras dure la pandemia.

\section{Lo evidente: la ciencia y el conocimiento}

La ciencia y el conocimiento no se encuentran, por supuesto, desligadas de lo anterior. Es decir, la ciencia es también una actividad social, con aspectos políticos y, por supuesto, éticos. Y lo mismo ocurre con el conocimiento en general. Pero parece que la ciencia, tanto aplicada como básica, ha cobrado importancia en estos últimos tiempos. Por un lado, todo lo que implica la comprensión del virus, la secuenciación de su ARN, los modos de propagación, su letalidad, etc., corresponden a la comprensión de los organismos, es decir, se trata de ciencia básica. Por el otro, las medidas a tomar para frenarlo, evitar la propagación, la prevención de la enfermedad, la vacuna, etc., es ciencia aplicada. En este momento, a pocos se les ocurre poner en cuestión la relevancia de la ciencia en nuestra sociedad, sobre todo de las ciencias biomédicas. ${ }^{4}$ Pero los científicos no

4 A la luz de las recientes manifestaciones en varios países europeos como Inglaterra, Italia, Alemania y Austria, contra la existencia del virus, me replanteo si esta afirmación es verdadera, pues son muchas las voces que afirman que esto es un movimiento para lucrar a la industria farmacéutica e imponer un estado totalitario y, por tanto, el virus es una invención, 
son lo mismo que los filósofos de la ciencia. Y sin embargo, ahí están los filósofos de la ciencia preparando números especiales sobre filosofía de la medicina y de la biología. Los filósofos de la medicina plantean cuestiones desde la ontología de la enfermedad, qué significa ser un paciente o, lo contrario, un sujeto sano, hasta cuestiones bioéticas acerca de los tratamientos y muchas otras que no relataré aquí. Ni que decir tiene que estos son temas que trascienden la situación actual. Pensar la medicina, cómo se hace, sus definiciones, sus métodos, los problemas de los diferentes sistemas es, por supuesto, algo que hacen los profesionales de la salud, pero el filósofo que aborda estas cuestiones tiene la posibilidad de ser un vínculo con la sociedad, como queda muy claro en toda la bioética. Y no solo con la sociedad, sino también con los especialistas, pues los filósofos pueden ser de ayuda a los científicos para pensar sus conceptos y sus temas.

Lo mismo podríamos decir de la filosofía de la biología, cuyo análisis y comprensión de conceptos biológicos se torna fundamental para entender la expansión y el funcionamiento de organismos. En este ámbito, en los últimos años un nuevo especialista, el filósofo de la ecología ha emergido con fuerza. La filosofía de la ecología aporta las herramientas críticas que conlleva la especulación filosófica a temas globales como el cambio climático, la conservación del medioambiente, la biodiversidad, etc. Muchos dirán que tanto de estos temas como de los relacionados con la medicina se ocupan los profesionales de cada área. Y nadie niega que así sea, pero eso no vuelve inútil la labor del filósofo. El entrenamiento que tiene un filósofo para pensar y repensar cuestiones, abordar temas desde diferentes perspectivas, utilizar diferentes herramientas para analizar conceptos, afinar definiciones, etc., torna su papel relevante, pues muchas veces los profesionales de las áreas se ven obligados a tomar medidas sin tener suficiente tiempo de meditarlas, y en estas cuestiones, un filósofo trabajando en equipos interdisciplinares puede ser de mucha ayuda. El filósofo puede aportar a casi todos los campos una perspectiva a un tiempo interna y externa. Es interna en la medida en que ha estudiado los temas y puede manejar los conceptos que manejan los profesionales, pero es externa porque no es un biólogo ni un médico, no trata las mismas cuestiones que un biólogo o un médico y no sigue sus mismos métodos.

Otro aspecto que últimamente se ha destacado mucho es la cuestión de los datos, cómo se comprenden, cómo se manejan, cómo se entiende una gráfica, etc. La comprensión de la estadística es algo que en principio todos lo que hemos tenido la suerte de ir a la escuela entendemos a niveles básicos. Los expertos nos muestran los números, los gráficos, las imágenes de los datos. Pero el modo en que se recogen, qué parámetros se utilizan, qué factores intervienen en su determinación es algo que no siempre nos cuestionamos. Por ejemplo, ¿por qué en Alemania se daba el promedio semanal de víctimas y contagios y en España la cifra diaria? ¿Qué hay detrás de esas decisiones por parte de las autoridades que comunican esos datos? ¿Cómo se comprende la diferencia entre una y otra información? Estas son preguntas que aclarar al ciudadano y que un filósofo que analice la estadística y la toma de datos debe saber responder. Ahora hemos mencionado los datos epidemiológicos, pero los medios de comunicación nos bombardean a diario con datos que son de este mismo tipo, estadísticas de educación, informe PISA, estadísticas de desempleo, de contratación, etc. La comprensión de las grandes cantidades de datos, su efecto, su recogida, su manipulación, es algo que tiene un gran alcance social y que tampoco puede quedar limitado al tiempo que dure una pandemia.

Ligada a la cuestión de los datos se encuentra el manejo de la información. Ha sido muy importante comprender todo lo que no sabíamos del virus: cómo se contrae, cómo se propaga, cuáles son los grupos más afectados, qué funciona y qué no funciona. Al mismo tiempo, se han multiplicado los canales de desinformación, los bulos, las fake news, las teorías de la conspiración, etc. Esta es una cuestión que ya venía gestándose hace tiempo. Nos hemos reído del terraplanismo y hemos tenido personajes terraplanistas en gobiernos de varios países. Nos hemos reído de los negacionistas del virus, y algunos son presidentes de gobierno. Las consecuencias que las redes de desinformación generan no son un problema solo en tiempos de pandemia. Lo sabemos, son peligrosas porque configuran las acciones de muchos miembros de la sociedad. En este sentido, problemas clásicos de la filosofía de la ciencia como el problema de la demarcación nunca

lo que torna a la ciencia y sus aplicaciones innecesarias a los ojos de muchos. Es esta una razón más que torna necesaria a la filosofía, pues si viviéramos en una sociedad más ilustrada, con mayor capacidad de contrastar la información, tal vez -y solo tal vez, de nuevo-, sucedería menos este tipo de manifestaciones. 
deben dejar de estar presentes en nuestros planes de estudios. De ello depende el aprender a distinguir la información veraz de la que no lo es.

En los últimos tiempos, las distorsiones de la realidad con el objetivo de manejar la opinión pública, es decir, eso que se ha llamado 'postverdad' se han convertido, pese al oxímoron, en un hecho. Ya nadie niega la capacidad de manipulación de las noticias falsas. La disolución operada sobre la verdad, la negación de los hechos frente a las interpretaciones, y este tipo de planteamientos avanzados por filósofos han tenido un efecto social que quizá sus propios proponentes no esperaban. La sociedad global hace apremiante el acceso a la información veraz, pero más apremiante hace aún la capacidad de los ciudadanos para discriminar información. He oído a ingenieros defender que la vacuna contra la Covid-19 es un invento de Bill Gates para insertarnos un chip que nos controle. Pero ellos mismos ceden a Google todos sus permisos de privacidad y dan acceso a Facebook a sus imágenes íntimas. Antes esto nos sonaría propio de alguien sin estudios, porque solo por tener estudios universitarios nos creíamos a salvo de estas cuestiones. Hoy hay médicos que alertan contra las vacunas, y nada de esto es una consecuencia de la pandemia en que nos encontramos ni desaparecerá cuando la pandemia se desvanezca. Por eso, es importante criticar el pensamiento mágico, tanto la confianza excesiva en la ciencia y la tecnología como la incomprensión en su funcionamiento y las manipulaciones de lo que se dice y, por qué no, afirmar con Badiou (2020):

mostraremos con valentía, públicamente, que las pretendidas 'redes sociales' muestra una vez más que ellas son (además del hecho de que engordan a los multimillonarios del momento) un lugar de propagación de la parálisis mental fanfarrona de los rumores fuera de control, del descubrimiento de las 'novedades' antediluvianas, cuando no es más que simple oscurantismo fascista (BARDIOU, 2020).

Es importante que estemos dispuestos a vivir sin certezas, que aprendamos a poner en cuestión aquello en lo que creemos, aunque contradiga nuestras íntimas convicciones, pero también es importante que aprendamos a conocer, a manejar la información, a contrastarla. Y no es importante solo ahora, lo ha sido siempre.

\section{Lo omnipresente: la ontología}

En los dos apartados anteriores nos hemos ocupado de cuestiones actuales y de ramas de la filosofía que parecerían haber acompañado el desarrollo de los tiempos. Lo social, lo ético y lo político van a estar siempre presentes en las sociedades humanas, como también lo estará el conocimiento y una de sus ramas, la ciencia. Pero parecería que, en el siglo XXI, ramas arcaicas como la metafísica y la ontología estarían desplazadas. Las preocupaciones metafísicas quedarían así guardadas para otros tiempos, productos de un pasado remoto demasiado especulativo. Y, sin embargo, ninguna de las otras puede hacerse sin ontología. Desde mi punto de vista la metafísica aislada no tiene sentido. Como filosofía primera si no se piensa en relación con lo que es, es decir, con todo lo demás, no pasa de una especulación de biblioteca, que puede ser muy interesante para intensas charlas de café con gafas de pasta, chaqueta de pana y aire afectado, pero que no acerca la filosofía al mundo en que uno vive. Esto supone la pérdida de sentido del planteamiento exclusivo por el ser. Hay que pensar en los entes. Los entes son virus, son organismos, son enfermedades, son sujetos políticos. Es decir, en la base de todo lo demás nos encontramos con el ente. El ente puede ser fluido y difuso, no tener fronteras bien definidas como lo que significa ser un sujeto sano o un enfermo potencial. Puede no ser tan simple como un balón de fútbol. Puede ser tan complejo como definir lo que es una universidad. Pero hay que hacerlo. Y no hay que dejar que esta tarea la hagan otros por nosotros. Y hay que hacerlo en relación al espacio que ocupa, a las relaciones que tiene. Pensar la ontología es una exigencia para comprender aquello de lo que hablamos, con lo que trabajamos, con lo que vivimos.

Pongamos un ejemplo reciente. A. Krenak, líder ecologista indigenista de la Amazonia, decía en una entrevista de este año: "la epidemia del coronavirus que se disemina por el mundo es una respuesta del planeta 
a la forma en que la sociedad viene consumiendo a la Tierra". Esta afirmación, si se entiende en un sentido metafórico (como hace Franco Berardi, 2020), puede servir para pensar las consecuencias de acciones como la deforestación, la pérdida de biodiversidad y otras muchas que son consecuencia del régimen expansionista y de esquilmar recursos en que hemos vivido mucho tiempo y aún vivimos. Ahora bien, para Krenak no parece una metáfora, si seguimos leyendo su entrevista, estas afirmaciones dan a entender su posición de manera literal. Krenak toma la naturaleza como capaz de vengarse, como un ente antropomorfizado. Y tiene una noción de que el mundo, al final se equilibra. Yo afirmo que esto es como pensar que todo tiene sentido y todo ocurre por una razón y nada fundamenta eso, más que una fe injustificada en el principio de razón suficiente. Eso sería caer en un leibnizianismo falaz, puesto que el pensamiento de Leibniz implica pensar que estamos en el mejor de los mundos posibles y, por tanto, no habría nada que cambiar, por eso la posición de Krenak es falaz, porque apela a la justicia natural -la venganza del virus- y al mismo tiempo a la necesidad de cambiar nuestro modo de vida. Si todo es justo, y al final se equilibra, ¿por qué cambiar nada? Pero Krenak apela a la necesidad de cambio, a que no podemos sin más 'volver a lo normal'. Pese a que él tenga razón en que no se puede -o sí se puede, pero no es deseable- volver sin más al modo de vida pre-pandemia, el argumento de partida se fundamenta en una ontología injustificada: la naturaleza es justa. Pero esa justicia es la que nos parece a los humanos. Es un equilibrio definido por nosotros. Yo no sé si la naturaleza es justa o no, o si siquiera puede aplicársele esta categoría, pero sé que vale la pena conocer las bases del sistema leibniziano y la ontología constitutiva del mejor de los mundos posibles para no sucumbir al impacto de grandes frases que puedan ser falaces.

Pensar la ontología no es una tarea que se vuelva más acuciante en pandemia. Es acuciante cuando un matemático intenta definir lo que sean los números reales. Es acuciante cuando un físico intenta entender qué tipo de ser tienen los neutrinos, que atraviesan la materia casi sin interaccionar con ella. Es acuciante cuando intentamos definirnos como responsables de nuestras acciones. Es acuciante porque está en todo lo que hacemos, vemos y decimos. Pero no es acuciante de manera aislada. Igual que el problema de la demarcación se vuelve inútil si no se piensa con otros agentes sociales como médicos, periodistas, jueces, biólogos, etc., la especulación metafísica que no se acerque a otros ámbitos de la filosofía, la ciencia y la sociedad se transforma en un mero juego académico. Esto no elude la importancia de que el filósofo se haya entrenado en ella y la conozca, no elude la importancia de que siga habiendo especialistas en Aristóteles y en Leibniz, pero es importante que estos, sean capaces de mostrar la relevancia de su conocimiento fuera de los muros de una biblioteca y del mundo académico.

\section{Lo olvidado: la historia}

Llegamos ahora a un punto extraño en nuestra argumentación. A lo largo del artículo he tratado de ir mostrando la necesidad del filósofo en las discusiones presentes, y ahora, lo que voy a mostrar es la necesidad de las discusiones pasadas. En nuestra sociedad, la historia es muchas veces ese 'gran olvidado. Cierto es que mucha gente repite la cantinela de que hay que conocer la historia para no repetir los errores del pasado. Una frase tantas veces reiterada que casi pierde sentido. Y, sin embargo, es cierta. Los historiadores de la filosofía son quizá una de las ramas más denostadas de nuestra profesión, parece como si solo se ocuparan de momias, de cosas que ya han ocurrido y ya no interesan a nadie. Los filósofos de la sociedad los consideran como reliquias académicas que solo tienen sentido bajo el polvo de las bibliotecas, los filósofos analíticos desprecian al historiador de la filosofía o de la ciencia pensando que es una tarea fácil por ocuparse de algo que ya ha sido, los post-modernos los han considerado como poco comprometidos, pese a servirse de ellos para hacer hermenéutica. No obstante, qué importante es un buen historiador.

Los historiadores de la filosofía tienen mucho que enseñarnos, mostrarnos que esto que ahora vivimos es nuevo y no lo es tanto. Un buen estudio sobre la descripción de la peste de Atenas en el De rerum natura de Lucrecio cobra hoy una sorprendente actualidad. Conocer y entender cómo hombres del pasado con algunos recursos muy diferentes a los nuestros -sobre todo la tecnología- pero con otros muy semejantes -un sistema 
político corrupto- se han enfrentado a lo que a ellos les pareció como una de las epidemias más graves de su tiempo, bien puede ayudarnos a conocernos y entendernos a nosotros mismos, a afrontar nuestra situación con más recursos. Igualmente, en el pasado han existido los bulos, la desinformación y el populismo. Grandes figuras como Lucrecio, Hobbes, D'Alembert han escrito sobre ello. Sobre situaciones diferentes con grandes semejanzas: crisis económicas, crisis sanitarias, crisis de confianza en la ciencia, estados totalitarios, corrupción de la monarquía y un largo etcétera. Un conocimiento erudito de estos autores, que es a lo que se dedica un historiador de la filosofía es capaz de enseñarnos reacciones personales y sociales que nos permitan desplegar y actualizar herramientas críticas. Entender cómo se produjo el debate sobre la bancarrota de la ciencia a finales del siglo XIX, o las guerras de la ciencia en los años 90 del siglo XX y cómo se luchó en estos frentes, cuáles fueron los argumentos, cómo se utilizó a la 'opinión pública', bien pueden servirnos para afrontar a los negacionistas del virus, a los terraplanistas y a muchos otros teóricos (y prácticos) de la conspiración. Pero no solo por el virus. Entender las luchas antirracistas del pasado, entender las condiciones históricas de emergencia de las desigualdades, todas esas son tareas importantes que los filósofos de la historia y los historiadores de la filosofía hacen en su día a día y su conocimiento, sus aportaciones, sus escritos tienen un impacto en el modo en que hoy pensamos y actuamos.

Por otra parte, una de las principales aportaciones de ese terreno tan denostado y olvidado que es la historia es la posibilidad de plantear visiones a largo plazo. Llevamos dos o tres décadas -si no más- asumiendo visiones cortoplacistas como si esta fuera la única opción viable. Vivir rápido, pensar poco y asumir que todo ha de cambiar a velocidad vertiginosa, ese parece ser el mantra de los últimos treinta años. El historiador y el filósofo de la historia tiene la posibilidad de parar el tiempo y examinar los momentos que elija, sean aquellos en que surge la ciencia, o un conflicto, o un problema económico. Y tiene la posibilidad de enseñarnos el largo recorrido de los acontecimientos. Las visiones a largo plazo ayudan a comprender las consecuencias de las acciones más allá de los cuatro años para los que se elige un gobierno. Pensar a largo plazo puede ayudarnos a cambiar de parecer con respecto a nuestras acciones en el planeta, nuestros sistemas educativos, nuestro modelo económico y otras muchas cosas. Muchos hemos crecido en la lógica de 'lo quiero y lo quiero ya', pensando que nuestros deseos, nuestras acciones, nuestros anhelos tenían que ser susceptibles de ser realizados en plazos muy breves, hemos aprendido la política del 'usar y tirar' como si fuera la única posible. Y no se trataba solo de los productos fabricados, sino también de las relaciones interpersonales e incluso de los planes de estudios. Eso ha fomentado la estructura de consumismo capitalista que ha invadido todas las esferas de nuestra vida, en la que la durabilidad ya no es un valor. Por eso no se trata de pensar solo en cómo resolver hoy las situaciones de la pandemia, sino de pensar a largo plazo para prevenir, para cuidarnos y cuidar nuestro entorno, se trata de comprender la multitud de acontecimientos que llevan a una determinada situación. Un ejemplo histórico es el análisis de Tolstói en Guerra y Paz sobre las múltiples condiciones que llevaron a la guerra entre Rusia y Francia en 1812, nos enseña la necesidad y la contingencia de ese acontecimiento, determinado por una pléyade de sucesos que parecen evitables y que, en conjunto, tornaron el conflicto inevitable. La historia nos hace capaces de pensar más allá del mañana, del ahora, del presente, nos ayuda a comprender los acontecimientos y a ponerlos en perspectiva. $Y$ eso es algo que la historia de la filosofía y la filosofía de la historia tienen que recordarnos cada día, no solo en tiempos de pandemia.

\section{Y. ¿por qué no?: la estética}

Pese a que el valor del arte por el arte es algo que aún se reconoce en ciertas esferas de la sociedad, con frecuencia se considera la estética como un área casi encerrada en sí misma. Se estudian los problemas del arte, los conceptos de belleza, el gusto y cuestiones semejantes, pero a menudo, se hace solo pensando en la misma obra de arte, sin relación con la esfera que la rodea. Si nos detenemos un poco, sin embargo, enseguida aparecen conexiones. Parece bastante obvia, en primer lugar, la relación con la historia, principalmente cuando tanto el gusto como lo bello se transforman en conceptos historizados y se asume que no son intemporales. Algo parecido ocurre cuando se piensa en los cánones de belleza en diferentes sociedades y 
entonces se asume que no son universales. Si lo pensamos un poco, casi toda área de la filosofía tiene tanta relación con la metafísica como con la estética. En matemáticas se habla de la belleza de los teoremas. Con frecuencia, en el desarrollo de teorías científicas se introducen valores que pueden considerarse estéticos como la simplicidad. Sin duda hay una estética en los discursos políticos: póngase por ejemplo el de Trump este año 2020 con ocasión de la celebración del 4 de julio en el monte Rushmore, con un decorado que hacía pensar en las escenografías preparadas por Mussolini en los años 30, una estética claramente fascista. El arte, bien lo saben los especialistas en estética, no es ajeno a los movimientos sociales, pensamos en la Bauhaus, en los carteles de los planes quinquenales de la Rusia estalinista, o en las pelucas propias del rococó.

La estética juega también un papel muy importante en cómo se dan las noticias, qué lenguaje se utiliza para transmitir determinada información, o incluso cómo se anuncian determinados productos. Hay una estética presente en la infantilización de nuestras sociedades actuales, en transformar a la juventud en un valor por sí mismo, e incluso en la elusión de responsabilidades hay una estética. La hay en mostrar sistemáticamente en televisión y en los medios de comunicación visuales el procedimiento por el que se hace una prueba PCR, en las fotografías de los cientos de féretros saliendo de los hospitales italianos o las fosas cavadas apresuradamente en Brasil. Siempre hay una estética, y siempre debe haber un análisis de lo que eso significa, de la percepción que produce, de los valores que genera. La labor del especialista en estética es tan importante como la de cualquier otro, porque por los sentidos percibimos el mundo que nos rodea, y cómo nos llegan las percepciones configura muchos aspectos de nuestros conocimientos, creencias y valores. Así que, sí, por qué no también, la estética.

\section{Conclusión: ¿ُReconstrucción?}

Me atrevería a decir que en las páginas precedentes hemos mostrado lo que era nuestro objetivo, a saber, la antítesis del título: que no hay tareas específicas de un filósofo en tiempos de pandemia. Que la pandemia no agudiza nuestra necesidad de pararnos y pensar, de realizar una reflexión pausada e informada, sino que esa necesidad está siempre ahí, que debería ser connatural al ser humano y, sobre todo, al ser social. La tarea del filósofo no cambia esencialmente, siempre es la tarea crítica. No solo la de realizar la crítica, sino la de incitar a ella. Puede que yo no esté de acuerdo con los artículos de Agamben, pero es bueno que él los escriba, porque me incitan a pensar, me despiertan el 'gusanillo' de la reflexión. Obligan a que medite sobre los temas.

La vida, el tiempo, el espacio están llenos de ocasiones para pensar. Ahora viene la necesidad de pensar la reconstrucción, pero esta no es nueva. Siempre hay temas sobre los que pensar, la ecología, la solidaridad, la economía. Intentemos participar con nuestro pensamiento, con nuestras voces, con nuestro estudio, con nuestra especialización, con nuestra docencia, del mundo en que queremos vivir. Hagamos que nuestras acciones sean pensadas. No necesitamos una pandemia o una crisis para leer a los filósofos. Siempre hace falta leerlos y hace falta que existan, que escriban, que estén presentes, como hacen falta los químicos, los matemáticos, los periodistas y los bailarines.

Los filósofos pueden aportar mucho cuando trabajan en equipos interdisciplinares, pero también pueden hacerlo mostrando diariamente la importancia del pensar, exponiendo que la filosofía es en realidad cosa de todos, que nos atañe a todos. Que pensar es algo que nadie puede hacer por nosotros. La tarea del filósofo es siempre la misma y al mismo tiempo diversa, es pensar y repensar, es ser molesto planteando problemas, pero también es incitar a pensar. Es estimular la discusión y el debate, el intercambio de puntos de vista, la existencia de la crítica para estar siempre vigilante, procurar generar una sociedad alerta, una sociedad atenta, una sociedad que piensa. 


\section{Referencias}

AMADEO, P. (ed.) Sopa de Wuhan. Pensamiento contemporáneo en tiempos de pandemias, ASPO, 2020.

AGAMBEN, Giorgio. La invención de una pandemia. In: AMADEO, P. (ed.) Sopa de Wuhan. Pensamiento contemporáneo en tiempos de pandemias, ASPO, 2020, p. 17-20.

BADIOU, Alain. Sobre la situación epidémica. In: AMADEO, P. (ed.) Sopa de Wuhan. Pensamiento contemporáneo en tiempos de pandemias, ASPO, 2020, p. 67-78.

BERARDI, Franco. Crónica de la Psicodeflación. In: AMADEO, P. (ed.) Sopa de Wuhan. Pensamiento contemporáneo en tiempos de pandemias, ASPO, 2020, p. 35-54.

BUTLER, Judith. El capitalismo tiene sus límites. In: AMADEO, P. (ed.) Sopa de Wuhan. Pensamiento contemporáneo en tiempos de pandemias, ASPO, 2020, p. 59-66.

KRENAK, Ailton. Voltar ao normal seria como se converter a negacionismo e aceitar que a Terra é plana. Entrevista em O Globo, 6 de abril de 2020, Disponible en: <https://oglobo.globo.com/cultura/voltar-ao-normal-seria-como-se-converter-negacionismo-aceitar-que-terra-plana-diz-ailton-krenak-24353229> Acesso em: 20 set 2020.

MICHEA, Jean-Claude. L’enseignement de l'ignorance. Paris: Éditions Climats, 1999.

MICHEA, Jean-Claude. La escuela de la ignorancia. MARTINEZ, Marc; Machado A. (Trad.) Madrid: Acuarela, 2018. 